McDonald, R. H., Goldberg, L. I., McNay, J. L. \& Tuttle, E. P. (1964). Effects of dopamine in man; augmentation of sodium excretion, glomerular filtration rate and renal plasma flow. J. clin. Invest., 43, 1116-1124.

Myers, J. B., Morgan, T. O., Carney, S. L. \& Ray, C. (1980). Effects of lithium on the kidney. Kidney Internat., 18, 601-608.

Parfrey, P. S., Ikeman, R., Anglin, D. \& Cole, C. (1983). Severe lithium intoxication treated by forced diuresis. Can. med. Ass. J., 129, 979-980.

Schou, M., Thomsen, K. \& Vestergaard, P. (1986).
The renal lithium clearance and its correlations with other biological variables: observations in a large group of physically healthy persons. Clin. Nephrol., 25, 207-211.

Thomsen, K. \& Schou, M. (1968). Renal lithium excretion in man. Am. J. Physiol., 215, 823-827.

Thomsen, K., Holstein-Rathlou, N. H. \& Leyssac, P. P. (1981). Comparison of three measures of proximal tubular reabsorption: lithium clearance, occlusion time and micropuncture. Am. J. Physiol., 241, F348-F355.

\title{
Misuse of the standard error of the mean
}

Two pharmacokinetic studies published in the March issue report data in terms of means and their standard errors: that by Scott et al. (1988) and that by Ferry et al. (1988). Both studies examined differences in kinetics between differing groups of subjects. Scott et al. (1988) compared healthy young and elderly volunteers, Ferry et al. (1988) compared patients with normal and with impaired renal function.

The question which these and similar studies address is whether the drug concerned should be used differently in elderly people, or patients with poor renal function, and if so in what ways. The prescriber has to make a decision about an individual, not about a group, and to answer the question we need to know the variability within the different groups. For instance, was the halflife of nifedipine longer in all the elderly subjects studied by Scott et al. (1988) than in all the young ones, or did the groups overlap? When only the standard errors of the means (s.e. mean) are reported, the reader has to make tedious calculations to find the answer. When standard deviations (s.d.) are given, the reader can, by doubling them, at once estimate the ranges. The data of

\section{References}

Ferry, N., Geoffroy, J., Pozet, N., Cuisinaud, G., Benzoni, D. \& Zech, P. Y. (1988). Influence of renal insufficiency on the pharmacokinetics of cicletanine and its effects on the urinary excretion of electrolytes and prostanoids. Br. J. clin. Pharmac., 25, 359-366.

Robertson, D. R. C., Waller, D. G., Renwick, A. G.
Robertson et al. (1988), who made similar comparisons and give s.d.s, show a clear overlap between young and elderly subjects.

In the study by Ferry et al. (1988) the healthy volunteers and the group with mild renal impairment overlap in terms of creatinine clearance and GFR; the overlap in GFR is obscured by use of the s.e. mean instead of the s.d. It is not surprising that the kinetics of cicletanine showed no difference between these two goups.

I beg you to banish such misuse of the s.e. mean from the Journal. This should not be difficult, since the majority of authors - at least in the March 1988 issue - correctly use s.d.s. I am glad to see your predecessor among them (Robertson et al., 1988).

\section{A. HERXHEIMER \\ Department of Clinical Pharmacology and Therapeutics, Charing Cross and Westminster Medical School, London W6 8RF}

Received 31 March 1988, accepted 4 May 1988

\& George, C. F. (1988). Age-related changes in the pharmacokinetics and pharmacodynamics of nifedipine. Br. J. clin. Pharmac., 25, 297-305.

Scott, M., Castleden, C. M., Adam, H. K., Smith, R. P. \& Fitzsimons, T. J. (1988). The effect of ageing on the disposition of nifedipine and atenolol. Br. J. clin. Pharmac., 25, 289-296. 